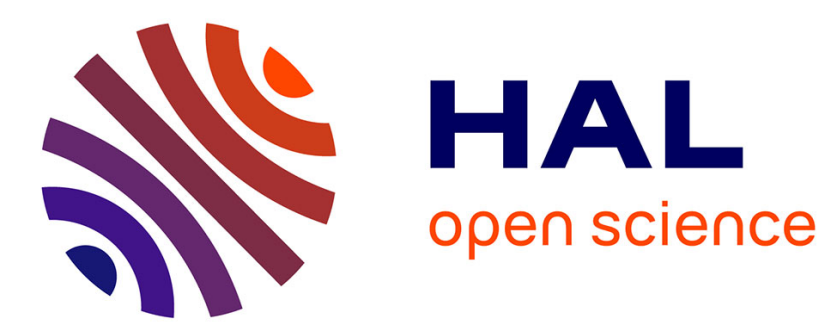

\title{
Trends in Plasticity of Metals and Alloys
}

Mikhail Lebyodkin, Vincent Taupin

\section{To cite this version:}

Mikhail Lebyodkin, Vincent Taupin. Trends in Plasticity of Metals and Alloys. Metals, 2021, 11 (4), pp.615. 10.3390/met11040615 . hal-03256715

\section{HAL Id: hal-03256715 https://hal.univ-lorraine.fr/hal-03256715}

Submitted on 5 Nov 2021

HAL is a multi-disciplinary open access archive for the deposit and dissemination of scientific research documents, whether they are published or not. The documents may come from teaching and research institutions in France or abroad, or from public or private research centers.
L'archive ouverte pluridisciplinaire HAL, est destinée au dépôt et à la diffusion de documents scientifiques de niveau recherche, publiés ou non, émanant des établissements d'enseignement et de recherche français ou étrangers, des laboratoires publics ou privés. 


\title{
Editorial
}

\section{Trends in Plasticity of Metals and Alloys}

\author{
Mikhaïl A. Lebyodkin $1,2, * \mathbb{C}$ and Vincent Taupin ${ }^{1,2}$ \\ 1 Laboratoire d'Etude des Microstructures et de Mécanique des Matériaux (LEM3), Université de Lorraine, \\ CNRS, Arts et Métiers ParisTech, 7 rue Félix Savart, 57000 Metz, France; vincent.taupin@univ-lorraine.fr \\ 2 Center of Excellence "LabEx DAMAS", Université de Lorraine, 7 rue Félix Savart, 57070 Metz, France \\ * Correspondence: mikhail.lebedkin@univ-lorraine.fr; Tel.: +33-(0)-372-747-771; Fax: +33-(0)-387-315-366
}

Citation: Lebyodkin, M.A.; Taupin, V. Trends in Plasticity of Metals and Alloys. Metals 2021, 11, 615. https:// doi.org/10.3390/met11040615

Received: 26 March 2021

Accepted: 7 April 2021

Published: 10 April 2021

Publisher's Note: MDPI stays neutral with regard to jurisdictional claims in published maps and institutional affiliations.

Copyright: (c) 2021 by the authors. Licensee MDPI, Basel, Switzerland. This article is an open access article distributed under the terms and conditions of the Creative Commons Attribution (CC BY) license (https:/ / creativecommons.org/licenses/by/ $4.0 /)$.
Having been at the center of technological progress for thousands of years, metals continue to be a primary material in our lives today. Investigations of the plasticity of crystalline solids, to which conventional metallic materials belong, were marked in the 20th century by a success in the understanding of microscopic mechanisms of plastic flow. This breakthrough was notably due to the development of experimental techniques allowing for the observation of individual defects, dislocations par excellence. The concurrent development of high-performance computers and numerical techniques gave rise to the hope that it would soon be possible to predict the mechanical behavior of bulk material by averaging the motions of individual defects, even if the sample contains myriads of defects.

However, investigations made during the last decades have shown that a fundamental property of plastic flow of solids is the self-organization of crystal defects. As a result, plastic flow is inherently heterogeneous and associated with complex dynamics and the formation of spatial structures in a mesoscopic scale range. Therefore, the understanding of the micro-macro transition inevitably implies investigation of local heterogeneities pertinent to the collective behavior of defects. On the other hand, the same period has seen considerable progress in the development of high-performance metals and alloys that possess enhanced mechanical properties ensured by complex microstructures. Ultrafinegrain materials, metallic glasses, gradient microstructures, etc. are gaining an increasing role in the industry. Therefore, the problem of the self-organization of defects comes to the fore as the characteristic lengths of the microstructure become comparable to the respective scales imposed by the collective deformation processes.

These challenges were a driving force for the development of sophisticated experimental techniques (in situ TEM, electron channeling contrast imaging, digital image correlation (DIC), nano-indentation, etc.), advanced multiscale modeling (molecular dynamics, discrete dislocation dynamics, strain gradient models, etc.), and methods of analysis of the observed and simulated complex spatiotemporal behaviors from the viewpoint of self-organization, with an aim of establishing process-microstructure-property links and filling gaps between the elementary atomic-scale mechanisms and the scale of a laboratory sample.

This Special Issue is composed of ten works presenting several topics within this huge and constantly developing domain. However, they touch upon all its basic pillars: new approaches to long-standing questions and traditional model materials allowing a deeper understanding of the underlying physical mechanisms, novel materials obtained by various processing routes, and advanced experimental and modeling techniques.

Paper [1] revisits a long-standing problem of work hardening processes and the possibility of reaching a steady state in unidirectional plastic deformation. This problem has recently received strong impetus due to the techniques of severe plastic deformation, which have made it possible to extend the attainable Von Mises equivalent strains from a unity value, limiting conventional tensile tests, to extraordinary values of $10^{5}$ in high pressure torsion. The paper provides a comprehensive review of the question and proposes an explanation for a new strain hardening stage revealed in such deformation processes. 
Achieving large strains and the elaboration of materials with complex microstructures put forward the need to take into account rotational modes of deformation, associated with disclinations. A review of field dislocation and disclination mechanics-a crystal plasticity model suggested about fifty years ago in a form based on continuous distributions of defects and developed to further include here the dynamics of rotational discontinuities-is given in [2]. Furthermore, the paper considers the application of this concept for modeling grain boundary-mediated plasticity.

Two works concern new approaches to the problem of fatigue behavior of materials $[3,4]$. In [3], the combination of the digital image correlation and electron backscatter diffraction techniques allows revealing the strong heterogeneities of strain and lattice rotation at the free surface of a tantalum polycrystalline aggregate during low cycle fatigue. The crystal plasticity finite element simulation confirms the strongly heterogeneous local ratcheting. These results allow the proposal of a new criterion for the initiation of local fatigue crack based on the local amount of ratcheting plastic strain. A cyclic plasticity model predicting strain range-dependent behavior is proposed and verified for austenitic steels in [4]. The model considers a virtual back stress, a new internal variable that allows the handling of the material behavior at large strain amplitudes.

Paper [5] revisits the problem of the mechanical characterization of ductile materials via compression tests and the limits of equivalence of tensile and compression test curves. This question being particularly essential in the case of alloys for medical purposes, the proposed compression test method is validated for several biomedical alloys.

Three papers then concern strain localization effects, each work considering this multifaceted problem under different angles and for distinct scale ranges [6-8]. The "autowave" phenomenon manifested by the occurrence of waves of strain localization during constantrate deformation is addressed in [6]. Such waves, usually characterized by rather low velocities $(<0.1 \mathrm{~mm} / \mathrm{s})$, have been observed in a large number of materials. To explain this phenomenon, a general approach based on the wave-particle duality is suggested with the aid of a quasi-particle representation relating waves and quasi-particles through the de Broglie equation. A dual character of self-organized deformation processes manifests itself directly, with no recourse to quantum theory, when a millisecond time resolution is attained. This is the case of [7], devoted to the investigation of the statistics of the local strain-rate field during the Portevin-Le Chatelier effect in an AlMg alloy. In addition to the large deformation bands that are characteristic of plastic instability, the high-frequency one-dimensional DIC technique reveals a wave-intermittency duality manifested by a wavy spatial organization of local plastic strain-rate bursts, which obey power-law statistics tantamount to avalanche-like deformation behavior. Strain localization at a considerably finer spatial scale pertaining to slip bands is considered in [8] for an Al-Cu-Li alloy prone to significant strain localization effects. By virtue of the interferometry technique, which allows the quantification of strain localization by assessing the surface roughness and computer simulations using discrete dislocation dynamics, the authors find evidence that the presence of Mn and $\mathrm{Zr}$ dispersoids may drastically homogenize the plastic strain in the investigated material.

Finally, two papers are devoted to nonconventional materials which are attracting strong attention in view of elaborating lighter materials and simultaneously improving mechanical properties $[9,10]$. A crystalline silver alloy with a complex microstructure associated with nanometric-size porosity obtained by selective chemical etching is studied in [9]. Using electron tomography and a nanoindentation technique, the paper aims at interpreting a highly heterogeneous mechanical behavior characterized by a complex relationship between the indenter penetration depth, the porosity, and the microstructure. The case of non-crystalline metallic materials is considered in [10], where nanoscale plasticity of bulk metallic glasses is studied theoretically for the case of a spherical nano-indenter. The work shows that plastic strain rearrangements, which describe plasticity in the absence of a long-range order, depend on the choice of the disorder. In particular, the conditions for the spatial organization leading to the formation of macroscopic shear bands are discussed. 
Acknowledgments: The guest editors would like to thank all authors who contributed to building this Special Issue and the reviewers for their comprehensive comments. The Editors of Metals journal are also warmly acknowledged for having proposed this opportunity and for their constant support. The guest editors would like to thank in particular the Editorial Assistant Kinsee Guo for invaluable help all along the preparation of this Special Issue.

Conflicts of Interest: The authors declare no conflict of interest.

\section{References}

1. Sevillano, J.G. Dynamic Steady State by Unlimited Unidirectional Plastic Deformation of Crystalline Materials Deforming by Dislocation Glide at Low to Moderate Temperatures. Metals 2020, 10, 66. [CrossRef]

2. Fressengeas, C.; Taupin, V. Revisiting the Application of Field Dislocation and Disclination Mechanics to Grain Boundary. Metals 2020, 10, 1517. [CrossRef]

3. Colas, D.; Finot, E.; Flouriot, S.; Forest, S.; Mazière, M.; Paris, T. Experimental and Computational Approach to Fatigue Behavior of Polycrystalline Tantalum. Metals 2021, 11, 416. [CrossRef]

4. Halama, R.; Fumfera, J.; Gál, P.; Kumar, T.; Markopoulos, A. Modeling the Strain-Range Dependent Cyclic Hardening of SS304 and 08Ch18N10T Stainless Steel with a Memory Surface. Metals 2019, 9, 832. [CrossRef]

5. Affolter, C.; Thorwarth, G.; Arabi-Hashemi, A.; Müller, U.; Weisse, B. Ductile Compressive Behavior of Biomedical Alloys. Metals 2020, 10, 60. [CrossRef]

6. Zuev, L.B.; Barannikova, S.A. Quasi-Particle Approach to the Autowave Physics of Metal Plasticity. Metals 2020, 10, 1446. [CrossRef]

7. Lebyodkin, M.; Bougherira, Y.; Lebedkina, T.; Entemeyer, D. Scaling in the Local Strain-Rate Field during Jerky Flow in an Al-3\%Mg Alloy. Metals 2020, 10, 134. [CrossRef]

8. Carrasco, E.J.; Chevy, J.; Davo, B.; Fivel, M. Effects of Manganese and Zirconium Dispersoids on Starin Localiation in Aluminum Alloys. Metals 2021, 11, 200. [CrossRef]

9. Champion, Y.; Laurent-Brocq, M.; Lhuissier, P.; Charlot, F.; Jorge, A.M., Jr.; Barsuk, D. Understanding the Interdependence of Penetration Depth and Deformation on Nanoindentaton of Nanoporous Silver. Metals 2019, 9, 1346. [CrossRef]

10. Tanguy, A.; Chen, P.; Chaise, T.; Nélias, D. Shear Banding in a Contact Problem between Metallic Glasses. Metals 2021, 11, 257. [CrossRef] 